\title{
Multicentric Reticulohistiocytosis Treated Successfully with Etanercept
}

\author{
C. Rodríguez-Cerdeira ${ }^{*}$, , B. Sánchez-Blanco ${ }^{1}$, San Millán B² and J.J. Vilata ${ }^{3}$ \\ ${ }^{I}$ Dermatology Department, CHUVI \& University of Vigo, Vigo, Spain \\ ${ }^{2}$ Pathology Department, CHUVI, Vigo, Spain \\ ${ }^{3}$ Dermatology Department, University of Valencia, Valencia, Spain
}

\begin{abstract}
Multicentric reticulohistiocytosis (MRH) is an uncommon systemic disease of unknown aetiology, which is characterized by the presence of papulonodular lesions, and is caused by the proliferation of histiocytes associated with arthritis. There are only just 200 cases described in the scientific literature. It can behave like a paraneoplasia and may be malignant in a quarter of the patients. We would like to add our patient to those described in the literature. Our patient was a 68 year-old male stonemason who was diagnosed of multicentric reticulohistiocytosis and was previously unsuccessfully treated with classical immunosupressants. The patient did, nonetheless, develop favourably with etanercept, with remission of the clinical and articular lesions.

In our opinion we feel that new treatment hopes will emerge for the treatment of inflammatory diseases where tumoral necrosis factor (TNF)-alpha and other cytokine production by monocytes and macrophages will play an important role.
\end{abstract}

Keywords: Multicentric reticulohistiocytosis, TNF-alpha, etanercept.

\section{INTRODUCTION}

Multicentric reticulohistiocytosis (MRH) is an uncommon systemic disease of unknown aetiology, which is characterized by the presence of papulonodular lesions, and is caused by the proliferation of histiocytes associated with arthritis. The term MRH was first used by Goltz and Laymon in 1954 [1] to distinguish it from cutaneous solitary reticulohistiocytosis [2], for describing patients showing destructive polyarthropathy and multiple cutaneous nodules. MRH is an uncommon condition with only 200 cases being described in the literature. It can behave like a paraneoplasia and can be malignant in a quarter of the patients. It occasionally gets better spontaneously.

\section{CASE REPORT}

The case is of a 68 -year-old male patient with multiple nodular lesions, which gradually appeared over a 4 year period, and which were accompanied by pruritus in the hands, arms and face. Multiple nodules were also observed on the right elbow and oedema in the left elbow. On the face we observed a nodule on the nasal pyramid (Fig. 1) and other smaller nodules in the nasal mucous membrane. The oral mucous membrane was free from lesions. Facial rash with xanthelasmas was observed; as well as sequels of predominantly bilateral polyarthritis, in the hands which caused their deformity (Fig. 1). Blood tests revealed GSR: 16; glucose: 121; uric acid: 3.1; PCR: 21; polyclonal hypergammaglobulinemia and FR: negative. Thoracic CAT revealed reticonodular infiltrate with a predomination of mean and upper fields, perilymphatic millimetric nodules, which caused retr-

\footnotetext{
*Address correspondence to this author at the Department of Dermatology, CHUVI, Meixoeiro Hospital \& University of Vigo, 36200 Vigo, Galicia, Spain; Tel: 0034600536114; Fax: 0034986276416;

E-mail: Carmen.Rodriguez.Cerdeira@sergas.es or

aristoteles_cerdeira@yahoo.es
}

action of the pulmonary architecture and fibrosis at the apexes. Pathological anatomy revealed a diffuse infiltrate of the dermis by histiocytes and giant multinucleate cells eosinophil pale, fine and granular cytoplasm. The cytoplasm of our cells was PAS positive (Figs. 2, 3). The patient was treated with various anti-inflammatory and anti-mitotic drugs, with scarce and intermittent improvement with the latest treatment regime being a combination of $40 \mathrm{mg}$ of oral methylprednisolone, omeprazol and weekly shots of $20 \mathrm{mg}$ of metrotexate. In previous studies and via immunohistochemical techniques the presence of histiocytes of monocytic-macrophagic origin and abundant cytokines was demonstrated, such as the TNF-alpha [3,4]. This led us to use etanercept at a dose of $25 \mathrm{mg}$ twice a week, and, later, $50 \mathrm{mg}$ weekly. The doses of the earlier drugs were progressively reduced. The patient's clinical cutaneous and articular symptoms are, at present, in the process of remission (Fig. 4). The improvement was particularly noteworthy from the fourth dose onwards.

\section{DISCUSSION}

The initial form of presentation in half the patients is of a polyarthritic type. Cutaneous lesions are common, in a quarter of the patients with papules and nodules. Another quarter part of the patients developed articular and cutaneous lesions at the same time. The cutaneous lesions are asymptomatic.

A third of the patients showed pruritus. Almost a third of the patients suffered constitutional symptoms such as weakness, weight loss and fever. The disease rapidly spreads at first, later diminishes and finally disappears. The cutaneous lesions are, in general, red or yellow-brown. The size may vary between papules of 1-2 mm till nodules of various centimetres in diameter. The lesions may be isolated or grouped, giving a cobble-stoned appearance. Thus they may coalesce into plates. In a third of the patients xanthelasma may develop, but this is not clearly related to MRH. Growth of the 

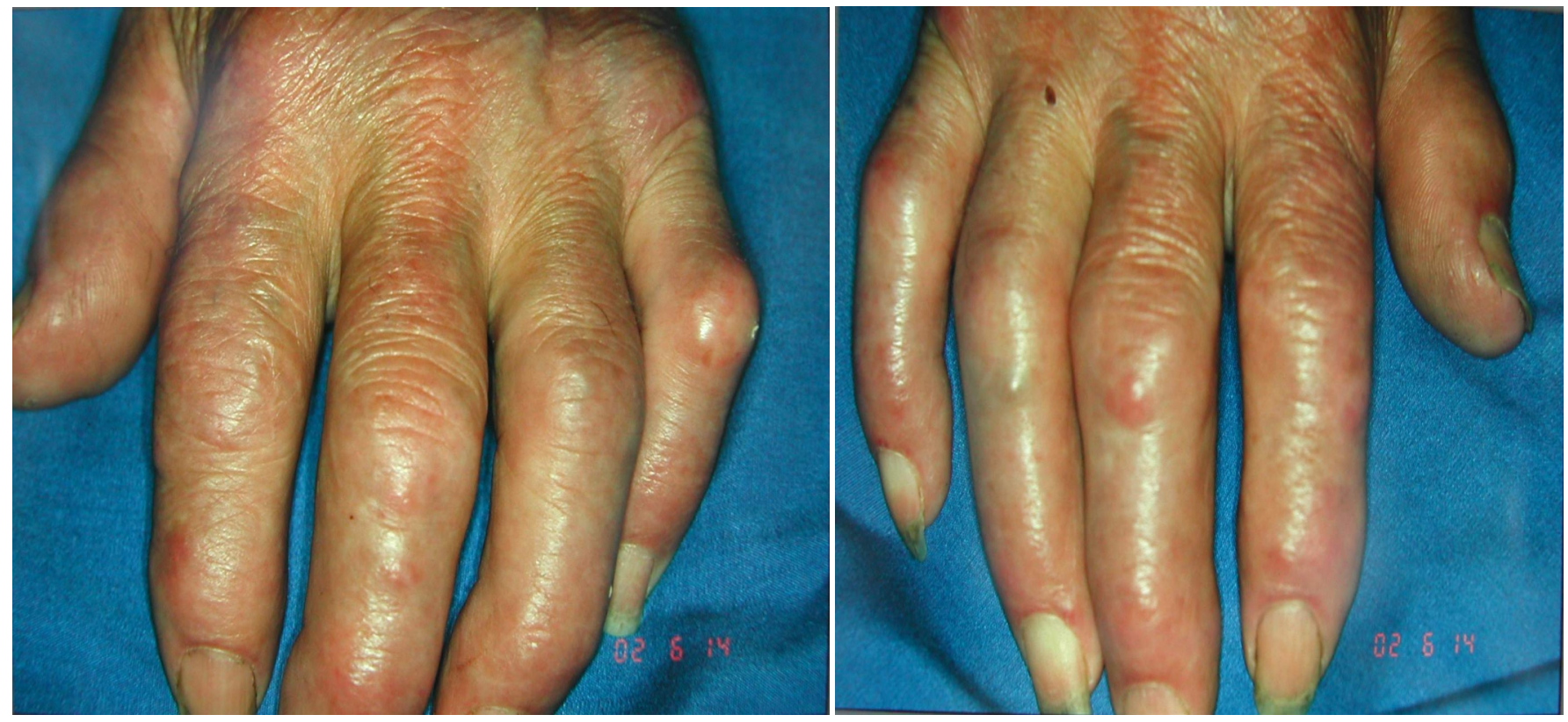

Fig. (1). Appearance of the hands with typical nodular lesions before treatment with anti-TNF-alpha.

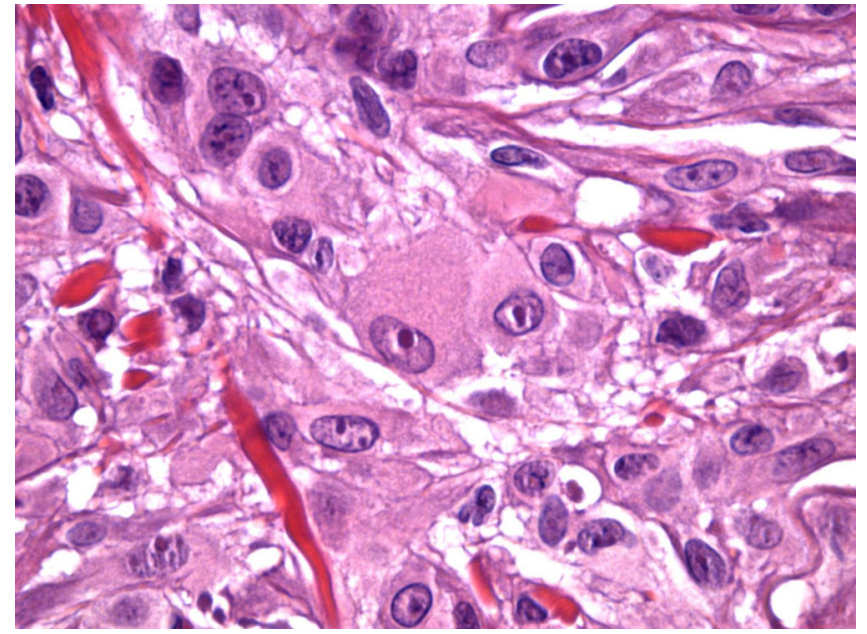

Fig. (2). Infiltrate composed of polygonal cells with wide cytoplasms, eosinophil "in polished glass" and oval nucleoli (Haematoxilin-eosin, x100).

nodules is slow and rarely leads to ulceration. The phenomenon of Koebner has been described in this disease. It is a weakening disease, which does not threaten the patient's life, except in those cases where it is associated with neoplastic processes. This is the same case as observed in spontaneous regression in a few isolated cases $[5,6]$

MRH is histologically characterized, in the skin, by a dense infiltrate in the dermis made from histiocytes and giant multinuclear cells. Both have dense finely granular eosinophil cytoplasms "in polished glass". Secondary alterations of the epidermis, principally hyperkeratosis, and flattening of the epidermal crests. Histochemically cellular cytoplasm stains uniformly with PAS-diastase. In the immunohistochemical study positive macrophage markers were observed (CD68, NAM 56, MAC 387) and negative markers for Lang-

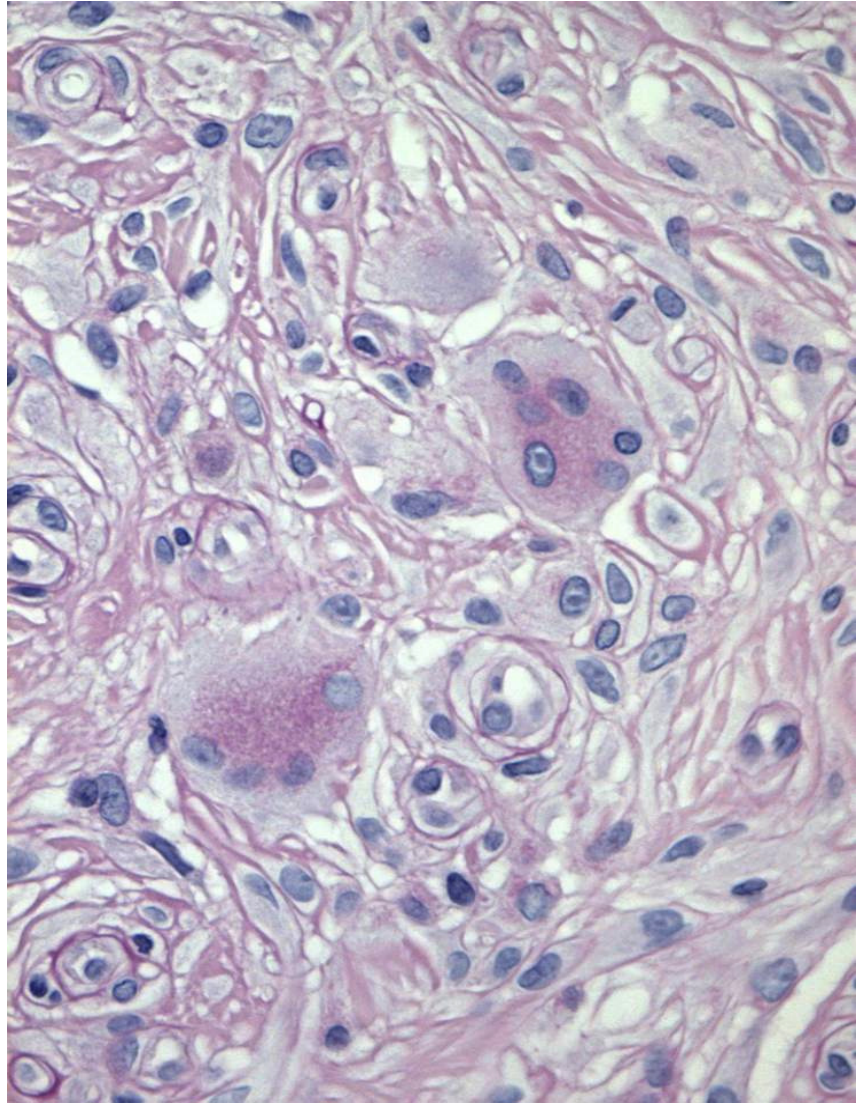

Fig. (3). The cytoplasm of our cells was PAS positive and sensitive to diastase digestion $(\mathrm{x} 40)$.

herans cells (CD1a, S100). We are dealing with a cellular proliferation of monocytic-marcophagic stock. Langherans granules were not perceivable under the electron microscope $[7,8]$. 


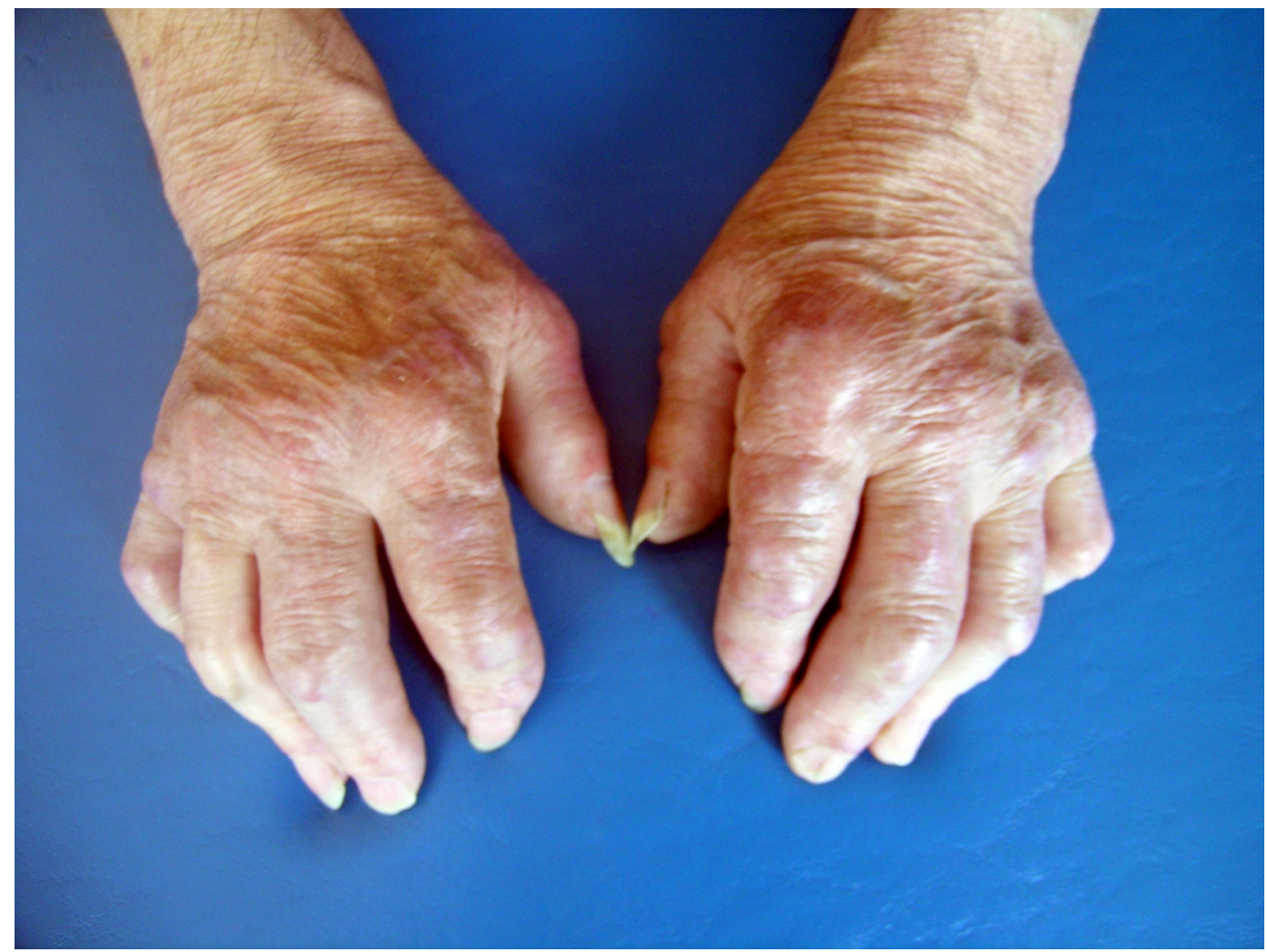

Fig. (4). Appearance of hands after one and a half years treatment with etanercept.

With regards to the laboratory study, half the patients, as occurred with our patients, had high sedimentation rates. Some were suffering from anaemia, diabetes, positive cryoglobulins, dyslipemia or hypergammaglobulinemia. This last anomaly was found in our patient. With regards to image studies, radiography revealed severe destruction of the cartilage and affected articulations. Typical lesions consisted of slight osteopenia and marked reabsorption of sub-chondral bone. Development of the lesions may be rapid and may even provoke mutilating arthritis. Radiological changes are often observed in the proximal and distal inter-phalangeal articulations. Osteoporosis is either minimal or absent. Neither sub-chondral sclerosis nor periosteal reactions have been observed.

Etnercept is a recombinant fusion protein of the soluble receptor of the TNF. It joins and is neutralized competitively and reversibly in both soluble TNF and when joined to the cellular membrane. It also neutralizes alpha lymphotoxin. Recently published papers provide MRH cases successfully treated with etanercept [9-12]. Nonetheless, results are controversial, since other authors such as Sellam et al. did not observe the expected improvement in these patients, to whom infliximab was also administered [13].

\section{CONCLUSIONS}

We believe that, with the arrival of biological therapies, new treatment hopes for inflammatory diseases in which TNF-alpha production and other cytokines by monocytes and macrophages play an important role, will emerge. TNFalpha is found in the synovial fluid of patients suffering from rheumatoid arthritis and in severe forms of inflammatory arthritis, as well as in patients with MRH. The notable improvement that appeared during the development of our patient, who was only treated with etanercept, reveals the efficacy of this medicine in this type of pathology on its own, and without judging it as a helper for other immunosuppressors. This makes it the preferred treatment for patients suffering from MRH with severe cutaneous manifestations whom have been seen to be resistant to treatment with classic immunosuppressors.

\section{REFERENCES}

[1] Goltz RW, Laymon CW. Multicentric reticulohistiocytosis of the skin and synovia; reticulohistiocytoma or ganglioneuroma. AMA Arch Derm Syphilol 1954; 69:717 -31.

[2] Caro MR, Senear FE. Reticulohistyocitoma of the skin. Arch Dermatol 1952; 65: 701-13.

[3] Gorman C, Danning C, Schumacher HR, Kippel JH, Davic JR Jr. Multicentric reticulohistiocytosis. A case report with immunohistochemical analysis and literature review. Arthritis Rheum 2000; 43: 930-8.

[4] Nakamura H, Yoshino S, Shiga H, Tanaka H, Katsuamta A. A case of spontaneous femoral neck fracture associated with multicentric reticulohistiocytosis analysis. Oversecretion of interleukin-1 beta, interleukin-6, and tumor necrosis factor alpha by affected synovial cells. Arthritis Rheum 1997; 40: 2266-70.

[5] Jansen TL, Kruithof Ig, Detmar M. Nodules in a patient with rheumatoid arthritis. Multicentric reticulohistiocytosis as a paraneoplastic manifestation. Ned Tijdschr Geneeskd 2003; 147: 1067.

[6] Malik MK, Regan L, Robinson-Bostom L, Pan T, Mcdonald CJ. Prolifereating multicentric reticulohistiocytosis associated papillary serous carcinoma of the endometrium. J Am Acad Dermatol 2005; 53: 1075-9.

[7] Baghestani S, Khosravi F, Dehghani Zahedani M, Mahboobi A. Multicentric reticulohistiocytosis presenting with papulonodular skin eruption and polyarthritis. Eur J Dermatol 2005; 15: 196-200. 
[8] Gajic-Veljic M, Nikolic MM, Bukilica M, Bonaci Nikolic B. Multicentric reticulohistiocytosis - a case with minimal articular changes. J Eur Acad Dermatol Venereol 2006; 20: 108-10.

[9] Kovach BT, Calamia KT, Walsh JS, Ginsburg WW. Treatment of multicentric reticulohistiocytosis with etanercept. Arch Dermatol 2004; 140: 919-21.

[10] Matejicka C, Morgan GJ, Schlegelmich JG. Multicentric reticulohistiocytosis treated successfully with anti-tumor necrosis factor agent. Artritis Rheum 2003; 48: 864-6.
[11] Rodríguez-Cerdeira C, Vilata JJ. Reticulohistiocitosis multicéntrica. Piel 2006; 21: 469-71.

[12] Lovelace K, Loyd A, Adelson D, Crowson N, Taylso JR, Cornelison R. Etanercept and the treatment of multicentric reticulohistiocytosis. Arch Dermatol 2005; 141: 1167-8.

[13] Sellam J, Deslandre CJ, Dubreuil F, Arfi S, Kahan A. Refractary multicentric reticulohistiocytosis treated by infliximab: two cases. Clin Exp Rheumatol 2005; 23: 97-9. 